\title{
PRIORITAS PENGEMBANGAN INDUSTRI DENGAN PENDEKATAN COMPETITIVE PRIORITIES
}

\author{
TRIFANDI LASALEWO \\ Jurusan Teknik Industri Universitas Negeri Gorontalo \\ E-mail: trifandi@yahoo.co.id
}

\begin{abstract}
ABSTRAK
Dalam proses mengembangkan keunggulan bersaing industri di suatu wilayah, mensyaratkan penetapan urutan prioritas kebijakan pembangunan industri berdasarkan kriteria/dimensi tertentu, dimana urutan ini didasarkan pada orientasi dan rencana pengembangan menurut perspektif para stakeholder industri diwilayah tersebut. Keunggulan bersaing ini berhubungan dengan tujuan industri dalam mencapai performansi terbaiknya dan strategi yang akan diterapkan agar suatu industri memiliki karakteristik unggul, sehingga dapat bertahan/memenangkan persaingan bisnis. Sebagai daerah baru, Provinsi Gorontalo membutuhkan skala prioritas yang dapat dijadikan acuan dan kerangka pengembangan industri dimasa yang akan datang. Model penelitian merupakan hasil pengembangan dari beberapa model competitive priorities (prioritas keunggulan bersaing) yang telah diterapkan di beberapa negara industri baru (New Industrialized Countries), sedangkan objek penelitian difokuskan pada Industri Kecil dan Menengah (IKM), mengingat IKM merupakan jumlah terbesar dalam kelompok industri di Provinsi Gorontalo. Berdasarkan survey dan hasil pengolahan data dengan menggunakan metode Law of Comparative Judgement (LCJ), diperoleh fakta bahwa terdapat 7 (tujuh) dimensi dominan yang harus dipertimbangkan dalam pengembangan industri yakni Kualitas (Quality), Biaya (Cost/Price), Sistem Pengiriman (Delivery), Fokus pada Konsumen (Customer Focus), Fleksibilitas (Flexibility), Kemampuan Berinovasi (Innovativeness), dan Berorientasi Pasar (Market Orientation). Urutan competitive priorities ini dapat juga diterapkan didaerah lain, mengingat karakter IKM yang menjadi objek penelitian ini pada dasarnya sama dengan karakter IKM didaerah lain di Indonesia.
\end{abstract}

Kata kunci: industri kecil menengah, competitive priorities, dan LCJ

\begin{abstract}
In the process of developing competitive advantages of industry in one area, it is required that order of priority of industrial development policies be based on certain kriteria/dimensions in which this order is based on the orientation and development plan according to the perspective of the stakeholders in that area. The competitive advantages are related to the purposes of industry in achieving its best performance and the strategy to be applied so that an industry possesses characteristics of competitive advantages that can survive/win business competition. As a new area, Gorontalo Province requires a scale of priority that can be made as a reference and industrial development plan in the future. The research model constitutes the results of several models of competitive priorities that have been established in several new industrialized countries; meanwhile the research object was focused on Small Medium Industry (SMIs) considering that SMIs are the biggest industrial group in Gorontalo Province. Based on the survey and results of data processing using The Law of Comparative Judgment (LCJ) method, there are 7 (seven) dominant dimensions that should be considered in developing industry; namely, Quality, Cost/Price, Delivery, Customer Focus, Flexibility, Innovativeness and Market Orientation. This order of competitive priorities can also be applied in other areas considering that the characters of SMI that are the object of the research are in principle the same as those of the SMI in other areas of Indonesia.
\end{abstract}

Keywords: small medium industry, competitive priorities, and LCJ

\section{PENDAHULUAN}

Penelitian yang dilakukan oleh UNTAD (United Nations Commission for Trade and Development) tahun 2005 pada beberapa kota di Thailand menemukan fakta pentingnya penentuan prioritas untuk memperbaiki manajemen rantai nilai (value chain management) dan keunggulan bersaing industri-industri yang tergabung dalam FTI
(Federation of Thai Industry) melalui continuous improvement (perbaikan berkesinambungan) dan competitive priorities (prioritas keunggulan bersaing) (Phusavat dan Kanchana, 2007). Menurut Laosirihongthong dan Dangayach (2005), prioritas suatu industri harus difokuskan pada improving product (perbaikan produk) dan proses yang berhubungan dengan kualitas dan delivery 
tepat waktu sehingga kriteria penting dalam keunggulan bersaing industri dapat dicapai dengan memperhatikan kualitas dan melaksanakan efisiensi. Hal yang sama juga dikemukakan oleh Barney et al. (2001), yang menyatakan bahwa keunggulan bersaing merupakan sumber dasar strategi yang merupakan kekuatan strategi bisnis saat ini (Takala et al., 2007).

Takala (2002) mengindikasi bahwa terdapat hubungan antara competitive priorities dengan manufacturing strategy, sedangkan Hoehn (2003) menyatakan pentingnya fokus pada competitive priorities guna menentukan masa depan perusahaan 5 (lima) tahun kedepan (Phusavat dan Kanchana (2007). Pada studi komparatif yang dilakukan Takala et al. (2007) juga terdapat hubungan antara competitive priorities dengan manufacturing strategy, dengan objek penelitiannya adalah 4 (empat) tipe perusahaan yang berbeda, sedangkan dimensi competitive priorities yang digunakan pada penelitiannya terdiri atas 6 (enam) dimensi yakni cost, quality, customer focus, know-how, logistics, dan flexibility.

Pengukuran competitive priorities digunakan untuk menentukan urutan prioritas kebijakan industri di suatu wilayah/negara. Menurut Askar dan Mortagy (2007), competitive priorities dapat dilakukan dari berbagai perspektif tergantung kebutuhan dan keadaan di suatu Negara. Untuk itu, diperlukan studi antara strategi manufaktur dengan karakteristik konsumen yang dilayani. Penelitian yang dilakukan oleh Askar dan Mortagy (2007) adalah untuk menentukan faktor prioritas yang perlu dipertimbangkan oleh perusahaan manufaktur dalam mengukur keunggulan bersaing dengan menggunakan 6 (enam) dimensi yang telah ditetapkan.

Pengukuran competitive priorities dapat juga digunakan sebagai tool oleh para manajer (pemimpin/ pemilik perusahaan) dalam mengoperasikan perusahaan mereka dan mengetahui kekuatan/ kelemahan yang dihadapi perusahaan. Untuk jangka panjang, pengukuran competitive priorities digunakan untuk mendukung proses pengambilan keputusan strategis bisnis perusahaan. Hayes dan Pisano (1996) berpendapat bahwa keputusan strategis terfokus dengan menggunakan competitive priorities tentunya sangat relatif bagi tiap perusahaan sehingga urutan prioritas yang dihasilkannya tentu berbeda (Askar dan Mortagy, 2007).

Pengukuran competitive priorities dalam penelitian ini dilakukan untuk menentukan urutan prioritas pengembangan industri dengan sampel penelitian adalah Provinsi Gorontalo, mengingat
Provinsi Gorontalo merupakan provinsi baru yang belum memiliki blue print pengembangan industri. Sedangkan yang menjadi objek penelitian adalah industri skala kecil dan menengah (IKM), dengan kriteria IKM menurut Badan Pusat Statistik dan UU RI No. 20 Tahun 2008. Kebijakan dalam menentukan urutan prioritas pengembangan industri merupakan suatu keputusan yang cukup kompleks dan rumit karena melibatkan banyak dimensi/variabel di dalamnya, di samping perbedaaan view point (sudut pandang) dari para stakeholder industri. Menurut Massa dan Testa (2008), perbedaaan ini umumnya dipengaruhi oleh perspektif, latar belakang kepentingan, orientasi pemikiran, dan tingkat pendidikan yang berbeda dari para stakeholder. Untuk itu, penelitian ini melibatkan unsur akademisi, pelaku usaha dan birokrat, atau yang lebih dikenal sebagai Triple Helix ABG (Academic, Business, Government) sebagai responden penelitian sebab ketiga stakeholder ini sangat berkepentingan terhadap pengembangan industri di tiap wilayah.

\section{METODE}

Model penelitian adalah sebuah model konseptual yang menggambarkan hubungan keterkaitan dan interaksi antar beberapa dimensi dalam penelitian. Dimensi-dimensi (dalam hal ini competitive priorities) penyusun model, diturunkan dari konsep teoritik yang dikembangkan oleh para ahli atau peneliti terdahulu, serta berasal dari gagasan baru untuk diuji dan diteliti lebih lanjut (Sekaran, 2003).

Berdasarkan studi literatur (diantaranya Phusavat dan Kanchana (2007), Askar dan Mortagy (2007), dan Takala et al. (2007)), diperoleh 11 (sebelas) dimensi penyusun competitive priorities (prioritas keunggulan bersaing), yang diuraikan dalam 62 sub dimensi, ditunjukkan pada Tabel 1.

Dari Tabel 1 dapat dilihat bahwa terdapat 11 dimensi competitive priorities yang mana semua dimensi tersebut memiliki subkriteria. Sebelas dimensi tersebut adalah kualitas, biaya, sistem pengiriman, flexibilitas, fokus pada konsumen, know how, kemampuan berinovasi, market orientation, progress technology, trading partner, dan institution support.

Pengurutan prioritas dimensi yang sesuai dengan karakteristik industri di Provinsi Gorontalo dilakukan dengan menggunakan pendekatan metode The Law of Comparative Judgement (LCJ). Salah satu kegunaan dari metode ini adalah untuk mengukur relative importance, yaitu semacam pembobotan untuk menggambarkan kepentingan relatif beberapa variabel/dimensi yang sesuai dengan karakteristik competitive priorities, dengan cara membandingkan 
Tabel 1. Dimensi Competitive Priorities Berdasar Literatur

\begin{tabular}{|c|c|c|c|}
\hline No. & Dimensi & SubDimensi & Literatur \\
\hline 1 & $\begin{array}{l}\text { Quality } \\
\text { (Kualitas) }\end{array}$ & $\begin{array}{ll}1.1 . & \text { Low Defect Rate } \\
\text { 1.2. } & \text { Product Performance } \\
\text { 1.3. } & \text { Product Reliability } \\
\text { 1.4. } & \text { Environmental Aspect } \\
\text { 1.5. } & \text { Certification } \\
\text { 1.6. } & \text { Conformance Quality } \\
\text { 1.7. } & \text { Product Durability } \\
\text { 1.8. } & \text { Design Quality }\end{array}$ & $\begin{array}{l}\text { Phusavat dan Kanchana (2007), } \\
\text { Takala et al. (2007), } \\
\text { Sharma dan Kodali (2008), } \\
\text { Laosirihongthong dan Dangayach (2005), } \\
\text { Dangayach dan Deshmukh (2005), } \\
\text { Gonzalez dan Vazquez (2007) }\end{array}$ \\
\hline 2 & $\begin{array}{l}\text { Cost/Price } \\
\text { (Biaya) }\end{array}$ & $\begin{array}{ll}2.1 . & \text { Low Cost } \\
\text { 2.2. } & \text { Volume Added Cost } \\
\text { 2.3. } & \text { Quality Cost } \\
\text { 2.4. } & \text { Activity-based Measurement } \\
\text { 2.5. } & \text { Continous Improvement } \\
\text { 2.6. } & \text { Lean Manufacturing }\end{array}$ & $\begin{array}{l}\text { Phusavat dan Kanchana (2007), } \\
\text { Gonzalez dan Vazquez (2007), } \\
\text { Askar dan Mortagy (2007), } \\
\text { Takala et al. (2007), } \\
\text { Laosirihongthong dan Dangayach (2005) }\end{array}$ \\
\hline 3 & $\begin{array}{l}\text { Delivery } \\
\text { (sistem pengiriman) }\end{array}$ & $\begin{array}{ll}\text { 3.1. } & \text { Fast Delivery } \\
\text { 3.2. } & \text { On Agreed Time } \\
\text { 3.3. } & \text { Right Quality } \\
\text { 3.4. } & \text { Right Amount } \\
\text { 3.5. } & \text { Dependable Promises } \\
\text { 3.6. } & \text { Supply Chain Management } \\
\text { 3.7. } & \text { Dependable Delivery } \\
\text { 3.8. } & \text { Delivery Speed }\end{array}$ & $\begin{array}{l}\text { Phusavat dan Kanchana (2007), } \\
\text { Askar dan Mortagy (2007), } \\
\text { Sharma dan Kodali (2008), } \\
\text { Laosirihongthong dan Dangayach (2005), } \\
\text { Dangayach dan Deshmukh (2005) }\end{array}$ \\
\hline 4 & $\begin{array}{l}\text { Flexibility } \\
\text { (fleksibilitas) }\end{array}$ & $\begin{array}{ll}\text { 4.1. } & \text { Design Adjustment } \\
\text { 4.2. } & \text { Volume Changes } \\
\text { 4.3. } & \text { Mix Changes } \\
\text { 4.4. } & \text { Broad Product Line } \\
\text { 4.5. } & \text { Flexible Processes } \\
\text { 4.6. } & \text { Design Changes } \\
\text { 4.7. } & \text { New Product Introduction } \\
\text { 4.8. } & \text { Product Customization } \\
\text { 4.9. } & \text { Product Flexibility } \\
\text { 4.10. } & \text { Volume Flexibility }\end{array}$ & $\begin{array}{l}\text { Phusavat dan Kanchana (2007), } \\
\text { Askar dan Mortagy (2007), } \\
\text { Takala et al. (2007), } \\
\text { Sharma dan Kodali (2008), } \\
\text { Laosirihongthong dan Dangayach (2005), } \\
\text { Dangayach dan Deshmukh (2005), } \\
\text { Gonzalez dan Vazquez (2007) }\end{array}$ \\
\hline 5 & $\begin{array}{l}\text { Customer Focus } \\
\text { (fokus pada konsumen) }\end{array}$ & $\begin{array}{ll}\text { 5.1. } & \text { After Sale Service } \\
\text { 5.2. } & \text { Product Customization } \\
\text { 5.3. } & \text { Product Support } \\
\text { 5.4. } & \text { Customer Information } \\
\text { 5.5. } & \text { Measurement of Satisfaction } \\
\text { 5.6. } & \text { Dependable Promises }\end{array}$ & $\begin{array}{l}\text { Phusavat dan Kanchana (2007), } \\
\text { Takala et al. (2007) }\end{array}$ \\
\hline 6 & Know How & $\begin{array}{ll}\text { 6.1. } & \text { Knowledge Management } \\
\text { 6.2. } & \text { Creativity } \\
\text { 6.3. } & \text { Continuous Learning } \\
\text { 6.4. } & \text { Problem Solving Skill } \\
\text { 6.5. } & \text { Training/education } \\
\text { 6.6. } & \text { Research \& Development }\end{array}$ & $\begin{array}{l}\text { Phusavat dan Kanchana (2007), } \\
\text { Takala et al. (2007) }\end{array}$ \\
\hline 7 & $\begin{array}{l}\text { Innovativeness } \\
\text { (kemampuan berinovasi) }\end{array}$ & $\begin{array}{ll}\text { 7.1. } & \text { Create New Market } \\
\text { 7.2. } & \text { Introduce New Product } \\
\text { 7.3. } & \text { Develop New Technology } \\
\text { 7.4. } & \text { Intellectual Property } \\
\text { 7.5. } & \text { Expand Foreign Market } \\
\text { 7.6. } & \text { Implement New Technology }\end{array}$ & $\begin{array}{l}\text { Askar dan Mortagy (2007), } \\
\text { Sharma dan Kodali (2008) }\end{array}$ \\
\hline 8 & Market Orientation & $\begin{array}{ll}\text { 8.1. } & \text { Export Oriented } \\
\text { 8.2. } & \text { Increase Capacity } \\
\text { 8.3. } & \text { Location }\end{array}$ & $\begin{array}{l}\text { Gonzalez dan Vazquez (2007), } \\
\text { Tambunan (2007) }\end{array}$ \\
\hline 9 & Progress Technology & $\begin{array}{ll}\text { 9.1. } & \text { Changging Technology } \\
\text { 9.2. } & \text { Growing Demand } \\
\text { 9.3. } & \text { Automated Technologies }\end{array}$ & Gonzalez dan Vazquez (2007) \\
\hline
\end{tabular}




\begin{tabular}{|c|c|c|c|}
\hline No. & Dimensi & SubDimensi & Literatur \\
\hline \multirow[t]{3}{*}{10} & Trading Partner & 10.1. Supplier Relationship & Gonzalez dan Vazquez (2007), Tambunan (2007) \\
\hline & & 10.2. Subcontracting Relationship & \\
\hline & & 10.3. Local Production Network & \\
\hline & Institution Support & 11.1. Policy \& Strategy & Tambunan (2007), \\
\hline & & 11.2. Investment Requirement & Massa dan Testa (2008) \\
\hline & & 11.3. Capital Assistance & \\
\hline
\end{tabular}

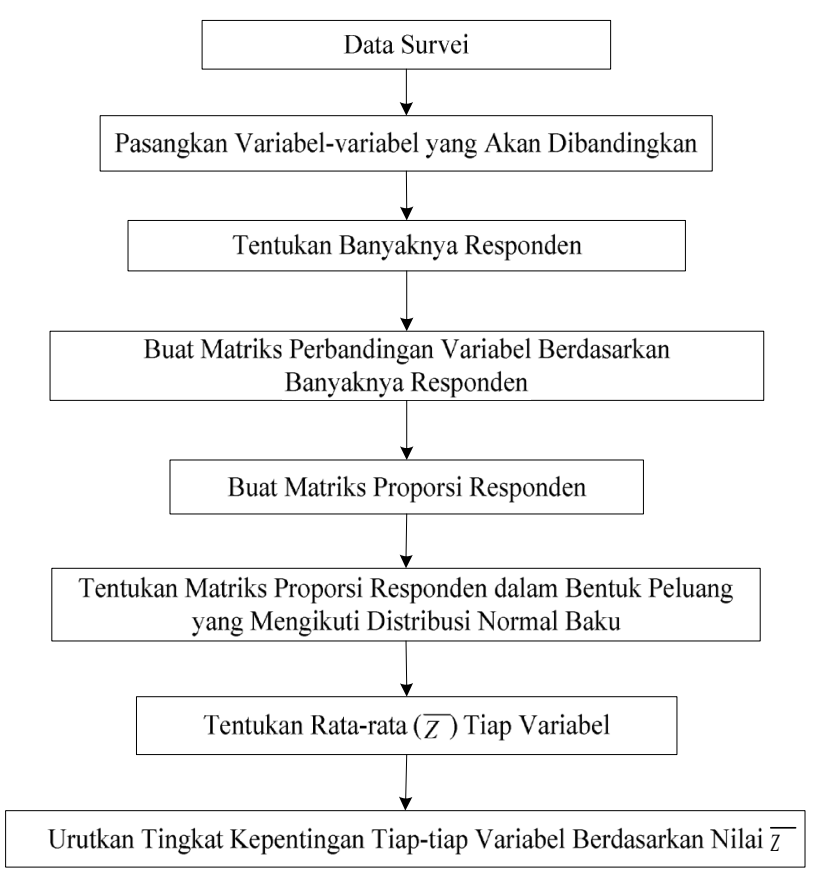

Gambar 1. Diagram Alur Metode Law of Comparative Judgement (LCG)

secara berpasangan antar dimensi penelitian. Urutan dengan menggunakan LCJ ini mengikuti langkahlangkah pada Gambar 1.

Dari Gambar 1 dapat dilihat bahwa yang pertama kali dilakukan untuk menentukan prioritas adalah melakukan survei. Dari data survey tersebut kemudian dapat dilakukan perbandingan variabelvariable secara berpasangan. Lalu dilakukan penentuan jumlah responden. Kemudian, matriks perbandingan variabel dibuat berdasarkan banyaknya responden. Setelah itu, mtariks proporsi responden dibuat. Matriks proporsi responden tersebut kemudian diubah menjadi bentuk peluang berdasarkan distribusi normal baku. Lalu, untuk setiap variabel, nilai rata-ratanya dihitung. Terakhir, tingkat kepentingan tiap-tiap variabel diurutkan berdasarkan nilai rata-rata yang telah diperoleh.

\section{HASIL DAN PEMBAHASAN}

Untuk mengumpulkan data primer mengenai urutan competitive priorities dari para responden, dilakukan melalui penyebaran kuesioner. Kuesioner pada penelitian ini berbentuk multiple-item scale dengan format Thurstone Scale, yang digunakan untuk mengukur sikap responden terhadap sejumlah objek (dimensi penelitian) dengan mengkombinasikan jawaban-jawaban tersebut menjadi skor rata-rata, dimana responden memilih 1 (satu) pertanyaan dari daftar respon yang dianggap paling tepat mewakili persepsi responden. Jumlah responden pada penelitian ini sebanyak 90 orang, yang terdiri atas unsur pelaku usaha, akademisi dan pemerintah. Secara statistik jumlah ini sampel ini sudah mencukupi, sebab menurut Supranto (2004) bahwa banyaknya responden yang diteliti berkisar 4-5 kali jumlah variabel (dimensi) penelitian. Dalam penelitian ini melibatkan 11 dimensi, sehingga sudah cukup dengan menggunakan 55 sampel saja. Sebagai perbandingan, banyaknya sampel yang digunakan oleh beberapa peneliti sebelumnya untuk mengukur

Tabel 2. Perbandingan Ruang Lingkup dan Jumlah Sampel Penelitian

\begin{tabular}{|c|c|c|c|c|c|}
\hline No & Peneliti & Tahun & Negara/Wilayah & Objek Sasaran & $\begin{array}{c}\text { Jumlah } \\
\text { Kuesioner }\end{array}$ \\
\hline 1 & Laosirihongthong dan Dangayach & 2005 & Thailand VS India & Otomotif & $122 \mathrm{IKM}$ \\
\hline 2 & Dangayach dan Deshmukh & 2005 & India & $\begin{array}{l}\text { Otomotif, elektronika, mesin \& } \\
\text { industri proses }\end{array}$ & $122 \mathrm{IKM}$ \\
\hline 3 & Askar dan Mortagy & 2007 & Mesir & Manufaktur, jasa \& Konstruksi & $120 \mathrm{IKM}$ \\
\hline 4 & Phusavat dan Kanchana & 2007 & Thailand & Otomotif, elektronik & 10 industri \\
\hline 5 & Gonzalez dan Vazquez & 2007 & Spanyol & Industri baja & 188 industri \\
\hline 6 & Sharma dan Kodali & 2008 & India & $\begin{array}{l}\text { Otomotif, mesin, elektronika, } \\
\text { industri proses \& Industri Tekstil }\end{array}$ & 72 industri \\
\hline 7 & Diaz et al. & 2005 & Spanyol & Industri Penerbangan & 20 industri \\
\hline 8 & Penelitian ini & 2009 & Provinsi Gorontalo & $\begin{array}{l}\text { Industri pengolahan, pangan, dan } \\
\text { industri kerajinan }\end{array}$ & $\begin{array}{l}90 \text { (IKM, akademisi } \\
\& \text { birokrat) }\end{array}$ \\
\hline
\end{tabular}


competitive priorities di suatu negara ditampilkan pada Tabel 2 berikut.

Dari hasil pemilahan karakteristik responden, diketahui bahwa pada umumnya responden yang terjaring dalam penelitian ini berjenis kelamin pria yakni sebanyak $61,11 \%$. Hal ini menunjukan bahwa pemilik IKM, akademisi dan birokrat yang merupakan responden penelitian lebih didominasi oleh pria. Di tinjau dari segi usia, sebagian besar responden yang terjaring dalam penelitian berada pada usia 26 sampai 35 tahun, yakni sebanyak 44\%, sedangkan responden usia dibawah 25 tahun dan usia diatas 55 tahun hanya sebagian kecil, yakni $7 \%$ dan $4 \%$, ditunjukkan pada Gambar 2. Hal ini menjelaskan bahwa pemilik IKM, akademisi dan birokrat yang merupakan responden dalam penelitian ini termasuk kategori usia produktif. Pada usia ini responden cenderung memiliki tingkat kematangan dalam berwirausaha dan kemampuan menganalisis lingkungan usaha.

Dilihat dari tingkat pendidikan, sebanyak $44 \%$ responden dengan tingkat pendidikan strata satu (S-1), dan 8\% menamatkan pendidikan S2/S3. Namun demikian ternyata masih terdapat $10 \%$ responden dengan tingkat pendidikan SD/SLTP. Secara keseluruhan ditinjau dari tingkat pendidikan responden yang terjaring dalam penelitian ini, memiliki pendidikan yang cukup baik, sehingga responden dapat memahami item-item pertanyaan dalam kuesioner. Pendidikan terakhir dari para responden ditampilkan pada Gambar 3.

Ditinjau dari masa kerjanya, responden yang ikut terjaring dalam penelitian ini sebagian besar memiliki masa kerja selama 6-10 tahun yakni 35\%, sedangkan yang memiliki masa kerja kurang dari 2 tahun hanya sebanyak $12 \%$. Hal ini mengindikasikan bahwa responden yang terjaring dalam penelitian ini telah memiliki pengalaman kerja yang cukup lama, sehingga mengetahui betul kondisi industri yang ada di Provinsi Gorontalo. Masa kerja responden ditampilkan pada Gambar 4.

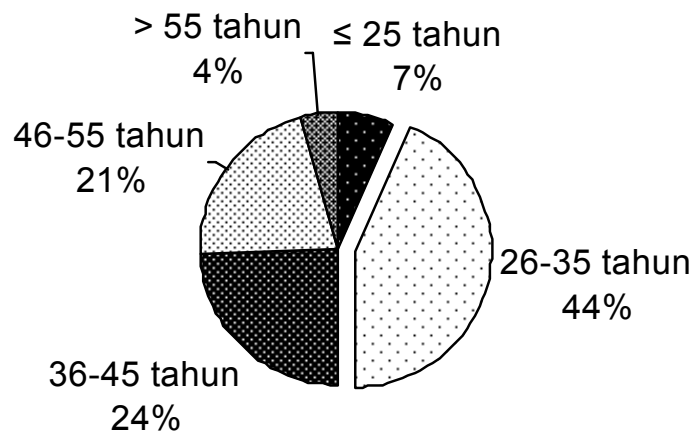

Gambar 2. Usia Responden Penelitian

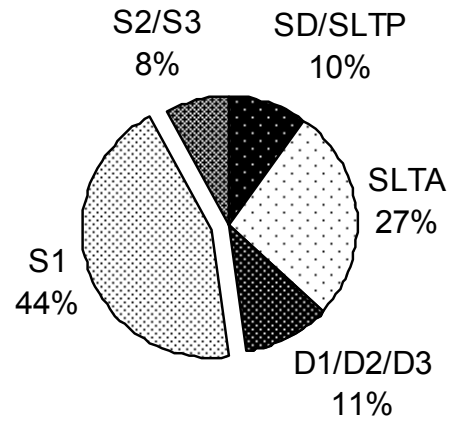

Gambar 3. Pendidikan Terakhir Responden

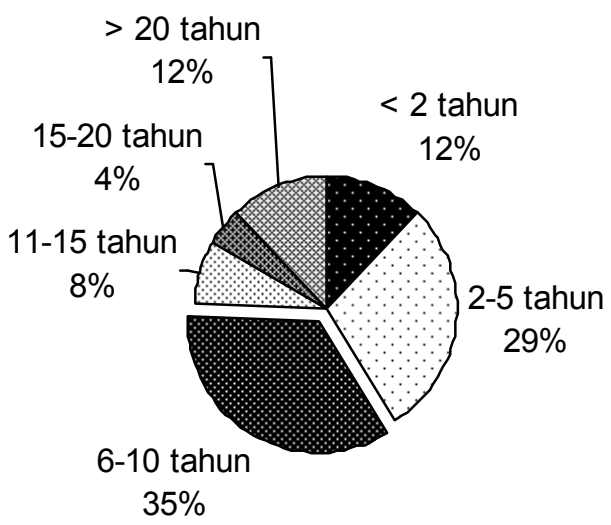

Gambar 4. Masa Kerja Responden

Tidak semua jawaban responden yang mengisi kuisioner dapat langsung diolah karena harus melalui tahap uji validitas. Suatu kuisioner dapat diolah jika reponden mengisi kuisioner dengan lengkap atau tidak terdapat circle (jawaban berputar) yang menunjukkan responden konsisten terhadap pilihan yang ditentukan. Setelah dilakukan validitas, dari 90 orang responden yang terjaring dalam penelitian, ternyata hanya ada 72 orang responden yang konsisten dalam menjawab pertanyaan kuisioner (valid) dan layak untuk dianalisis lebih lanjut. Secara statistik, jumlah sampel yang valid ini sudah mencukupi batas minimal sampel, yakni 55 buah sampel. Perhitungan uji validitas atas jawaban konsumen ditampilkan pada Tabel 3.

Berdasarkan Tabel 3 di atas, dari perbandingan kolom terhadap barisnya diketahui bahwa ketika dimensi X1 dibandingkan dengan dimensi X2, responden lebih memilih dimensi X1. Ketika dimensi $\mathrm{X} 1$ dibandingkan dengan dimensi X5, responden lebih memilih dimensi X5. Tetapi ketika dimensi X2 dibandingkan dengan dimensi $\mathrm{X} 5$, ternyata responden lebih memilih dimensi X2. Dari hal ini terlihat adanya jawaban berputar pada pilihan responden tersebut dan ini menunjukkan ketidakkonsistensian responden dalam menjawab kuisioner. Dengan demikian dapat dilihat secara kasat mata, jawaban 
seorang responden dikatakan valid jika urutan angka yang berada pada baris "jumlah" terurut dari angka terbesar menuju angka terkecil.

Tahap selanjutnya adalah menghitung matriks hasil penilaian para responden. Pada tahap ini, setiap dimensi dijumlahkan berdasarkan tingkat kepentingannya dan jawaban tersebut dicatat dalam bentuk matriks yang disajikan pada Tabel 4 berikut.

Sebagai contoh, ketika dimensi X2 dan X3 dibandingkan dengan dimensi $\mathrm{X} 1$, dimana dimensi X2 dan X3 memiliki kepentingan yang lebih besar

Tabel 3. Ranking Dimensi Competitive Priorities

\begin{tabular}{lccc}
\hline \multicolumn{1}{c}{ Dimensi } & $\begin{array}{c}\text { Tingkat } \\
\text { Kepentingan }\end{array}$ & \% & Kumulatif\% \\
\hline X1: Quality & 3,40 & 14,45 & 14,45 \\
X2: Cost/Price & 3,14 & 13,33 & 27,78 \\
X3: Delivery & 2,74 & 11,65 & 39,43 \\
X5: Customer Focus & 2,60 & 11,03 & 50,46 \\
X4: Flexibility & 2,48 & 10,54 & 61,00 \\
X7: Innovativeness & 1,94 & 8,23 & 69,24 \\
X8: Market Orientation & 1,71 & 7,26 & 76,50 \\
X6: Know How & 1,69 & 7,19 & 83,69 \\
X9: Progress Technology & 1,52 & 6,45 & 90,14 \\
X10: Trading Partner & 1,32 & 5,61 & 9 \\
X11: Institution Support & 1,00 & 4,26 & 95,74 \\
Jumlah & 23,55 & & 100,00 \\
\hline
\end{tabular}

Keterangan: Angka 1 menunjukkan memilih alternatif pertama, angka 0 menunjukkan memilih alternatif kedua

Tabel 4. Matriks Perbandingan Dimensi

\begin{tabular}{|c|c|c|c|c|c|c|c|c|c|c|c|}
\hline & X1 & X2 & X3 & $\mathrm{X4}$ & X5 & X6 & X7 & X8 & X9 & $\mathbf{X 1 0}$ & $\mathrm{X11}$ \\
\hline $\mathrm{X} 1$ & 0 & 26 & 6 & 5 & 10 & 2 & 4 & 7 & 4 & 4 & 4 \\
\hline $\mathrm{X} 2$ & 45 & 0 & 16 & 8 & 16 & 4 & 8 & 8 & 4 & 6 & 4 \\
\hline X3 & 66 & 56 & 0 & 20 & 29 & 4 & 9 & 8 & 10 & 7 & 4 \\
\hline $\mathrm{X} 4$ & 67 & 64 & 52 & 0 & 33 & 5 & 15 & 14 & 11 & 7 & 5 \\
\hline X5 & 62 & 56 & 43 & 39 & 0 & 6 & 20 & 13 & 7 & 8 & 3 \\
\hline $\mathrm{X} 6$ & 70 & 68 & 68 & 67 & 66 & 0 & 35 & 27 & 20 & 16 & 6 \\
\hline $\mathrm{X} 7$ & 68 & 64 & 63 & 57 & 52 & 36 & 0 & 24 & 24 & 15 & 5 \\
\hline $\mathrm{X} 8$ & 65 & 64 & 64 & 58 & 59 & 45 & 48 & 0 & 31 & 25 & 12 \\
\hline X9 & 68 & 68 & 62 & 61 & 65 & 52 & 48 & 41 & 0 & 26 & 20 \\
\hline $\mathrm{X} 10$ & 68 & 66 & 65 & 65 & 64 & 56 & 57 & 47 & 46 & 0 & 33 \\
\hline $\mathrm{X} 11$ & 68 & 68 & 68 & 67 & 69 & 66 & 67 & 60 & 52 & 39 & 0 \\
\hline
\end{tabular}

Tabel 5. Matriks Proporsi

\begin{tabular}{llllllllcccccc}
\hline & $\mathbf{X 1}$ & \multicolumn{1}{c}{$\mathbf{X 2}$} & $\mathbf{X 3}$ & $\mathbf{X 4}$ & $\mathbf{X 5}$ & $\mathbf{X 6}$ & $\mathbf{X 7}$ & $\mathbf{X 8}$ & $\mathbf{X 9}$ & $\mathbf{X 1 0}$ & $\mathbf{X 1 1}$ \\
\hline X1 & 0 & 0,361 & 0,083 & 0,069 & 0,139 & 0,028 & 0,056 & 0,097 & 0,056 & 0,056 & 0,056 \\
X2 & 0,639 & 0 & 0,222 & 0,111 & 0,222 & 0,056 & 0,111 & 0,111 & 0,056 & 0,083 & 0,056 \\
X3 & 0,917 & 0,778 & 0 & 0,278 & 0,403 & 0,056 & 0,125 & 0,111 & 0,139 & 0,097 & 0,056 \\
X4 & 0,931 & 0,889 & 0,722 & 0 & 0,458 & 0,069 & 0,208 & 0,194 & 0,153 & 0,097 & 0,069 \\
X5 & 0,861 & 0,778 & 0,597 & 0,542 & 0 & 0,083 & 0,278 & 0,181 & 0,097 & 0,111 & 0,042 \\
X6 & 0,972 & 0,944 & 0,944 & 0,931 & 0,917 & 0 & 0,500 & 0,333 & 0,333 & 0,208 & 0,069 \\
X7 & 0,944 & 0,889 & 0,875 & 0,792 & 0,722 & 0,500 & 0 & 0,333 & 0,333 \\
X8 & 0,903 & 0,889 & 0,889 & 0,806 & 0,819 & 0,625 & 0,667 & 0 & 0,208 & 0,069 \\
X9 & 0,944 & 0,944 & 0,861 & 0,847 & 0,903 & 0,722 & 0,667 & 0,569 & 0 \\
X10 & 0,944 & 0,917 & 0,903 & 0,903 & 0,889 & 0,778 & 0,792 & 0,653 & 0,639 & 0 \\
X11 & 0,944 & 0,944 & 0,944 & 0,931 & 0,958 & 0,917 & 0,931 & 0,833 & 0,722 & 0,542 & 0 \\
\hline
\end{tabular}


dibandingkan dimensi X1, maka dari 72 orang reponden terdapat 26 responden yang menilai bahwa dimensi X2 lebih penting dari dimensi X1, dan dari 72 responden hanya terdapat 6 orang responden yang menilai X3 lebih penting dari X1, dan seterusnya.

Berikutnya dibuat matriks proporsi. Matriks proporsi didapatkan dengan cara membagi setiap nilai pada Tabel 4 di atas dengan banyaknya jumlah responden yang valid (72 orang). Matriks proporsi disajikan pada Tabel 5. Kemudian, matriks proporsi di Tabel 5 diubah menjadi matriks baku menggunakan tabel distribusi normal. Matriks baku akan disajikan pada Tabel 6.

Kemudian, matriks jumlah nilai $\mathrm{Z}$ dan ratarata dihitung. Matriks ini diperoleh dengan cara menjumlahkan nilai pada masing-masing kolom pada Tabel 6, lalu dihitung rata-ratanya. Matriks ini ditampilkan pada Tabel 7.

Tahap selanjutnya adalah membuat matriks transformasi nilai. Pada Tabel 7 di atas, rata-rata dimensi terbesarnya adalah X11 dengan nilai -1,14. Selanjutnya, nilai tersebut diubah menjadi nilai 1. Cara perubahan nilai tersebut adalah $-1,14+$ $\mathrm{A}=1$. Maka, $\mathrm{A}=1+1,14=2,14$. Seterusnya semua dimensi ditambahkan dengan nilai 2,14 sehingga diperoleh hasil seperti yang disajikan pada Tabel 8 .

Pada Tabel 9 dapat dilihat bahwa dimensi X11 yakni institution support merupakan dimensi yang paling kecil pengaruhnya $(1,00)$, sedangkan pengaruh yang paling besar adalah variabel/dimensi x1, yakni quality (dengan nilai 3,403 kali dimensi X11). Tabel 8 sekaligus merangkingdimensi prioritas keunggulan bersaing industri.

Setelah dilakukan metode LCJ, maka diperoleh urutan dimensi prioritas pengembangan industri yang ditunjukkan pada Tabel 9, yang menggambarkan persentase tingkat kepentingan. Berdasarkan kebiasaan bahwa banyaknya informasi kumulatif persentase kepentingan yang ingin diketahui berkisar antara 75\%-80\% dan dalam penelitian ini

Tabel 6. Matriks Baku

\begin{tabular}{|c|c|c|c|c|c|c|c|c|c|c|c|}
\hline & $\mathbf{X 1}$ & X2 & X3 & $\mathrm{X4}$ & X5 & X6 & $\mathbf{X 7}$ & $\mathbf{X 8}$ & $\mathbf{X 9}$ & X10 & X11 \\
\hline $\mathrm{X} 1$ & 0 & $-0,355$ & $-1,383$ & $-1,480$ & $-1,085$ & $-1,915$ & $-1,593$ & $-1,298$ & $-1,593$ & $-1,593$ & $-1,593$ \\
\hline $\mathrm{X} 2$ & 0,355 & 0 & $-0,765$ & $-1,221$ & $-0,765$ & $-1,593$ & $-1,221$ & $-1,221$ & $-1,593$ & $-1,383$ & -1.593 \\
\hline X3 & 1,383 & 0,765 & 0 & $-0,589$ & $-0,246$ & $-1,593$ & $-1,150$ & $-1,221$ & $-1,085$ & $-1,298$ & $-1,593$ \\
\hline $\mathrm{X} 4$ & 1,480 & 1,221 & 0,589 & 0 & 0,006 & $-1,480$ & -0.812 & $-0,862$ & $-1,025$ & $-1,298$ & $-1,480$ \\
\hline $\mathrm{X} 5$ & 1,085 & 0,765 & 0,246 & 0,105 & 0 & $-1,383$ & $-0,589$ & 0,913 & $-1,298$ & $-1,221$ & $-1,732$ \\
\hline $\mathrm{X} 6$ & 1,915 & 1,593 & 1,593 & 1,480 & 1,383 & 0 & 0,000 & $-0,319$ & $-0,589$ & $-0,765$ & $-1,383$ \\
\hline $\mathrm{X} 7$ & 1,593 & 1,221 & 1,150 & 0,812 & 0,589 & 0,000 & 0 & $-0,431$ & $-0,31$ & $-0,812$ & $-1,480$ \\
\hline $\mathrm{X} 8$ & 1,298 & 1,221 & 1,221 & 0,862 & 0,913 & 0,319 & 0,431 & 0 & $-0,175$ & $-0,393$ & $-0,967$ \\
\hline $\mathrm{X} 9$ & 1,593 & 1,593 & 1,085 & 1,025 & 1,298 & 0,589 & 0,431 & 0,175 & 0 & $-0,355$ & $-0,589$ \\
\hline $\mathrm{X} 10$ & 1,593 & 1,383 & 1,298 & 1,298 & 1,221 & 0,765 & 0,812 & 0,393 & 0,355 & 0 & $-0,105$ \\
\hline $\mathrm{X} 11$ & 1,593 & 1,593 & 1,593 & 1,480 & 1,732 & 1,383 & 1,480 & 0,967 & 0,589 & 0,105 & 0 \\
\hline
\end{tabular}

Tabel 7. Jumlah dan Rata-rata Tiap Dimensi

\begin{tabular}{|c|c|c|c|c|c|c|c|c|c|c|c|}
\hline Nilai & X1 & $\mathrm{X2}$ & X3 & $\mathrm{X} 4$ & $\mathrm{X5}$ & X6 & $\mathrm{X7}$ & X8 & X9 & $\mathbf{X 1 0}$ & X11 \\
\hline Jumlah & 13,889 & 10,999 & 6,628 & 3,770 & 5,045 & $-4,908$ & $-2,212$ & $-4,728$ & $-6,844$ & $-9,013$ & $-12,52$ \\
\hline Rata-rata & 1,263 & 1,00 & 0,603 & 0,343 & 0,459 & $-0,446$ & $-0,201$ & $-0,430$ & $-0,622$ & $-0,819$ & $-1,14$ \\
\hline
\end{tabular}

Tabel 8. Matriks Transformasi Nilai

\begin{tabular}{cccc}
\hline Variabel & Rata-rata & Jumlah & Rangking \\
\hline X1 & $1,26+2,14$ & 3,40 & 1 \\
X2 & $1,00+2,14$ & 3,14 & 2 \\
X3 & $0,60+2,14$ & 2,74 & 3 \\
X4 & $0,34+2,14$ & 2,48 & 5 \\
X5 & $0,46+2,14$ & 2,60 & 4 \\
X6 & $-0,45+2,14$ & 1,69 & 8 \\
X7 & $-0,20+2,14$ & 1,94 & 6 \\
X8 & $-0,43+2,14$ & 1,71 & 7 \\
X9 & $-0,62+2,14$ & 1,52 & 9 \\
X10 & $-0,82+2,14$ & 1,32 & 10 \\
X11 & $-1,14+2,14$ & 1,00 & 11 \\
\hline
\end{tabular}


Tabel 9. Ranking Dimensi Competitive Priorities

\begin{tabular}{lcccc}
\hline \multicolumn{1}{c}{ Dimensi } & $\begin{array}{c}\text { Tingkat } \\
\text { Kepentingan }\end{array}$ & \% & Kumulatif\% & Rangking \\
\hline X1: Quality & 3,40 & 14,45 & 14,45 & 1 \\
X2: Cost/Price & 3,14 & 13,33 & 27,78 & 2 \\
X3: Delivery & 2,74 & 11,65 & 39,43 & 3 \\
X5: Customer Focus & 2,60 & 11,03 & 50,46 & 4 \\
X4: Flexibility & 2,48 & 10,54 & 61,00 & 5 \\
X7: Innovativeness & 1,94 & 8,23 & 69,24 & 6 \\
X8: Market Orientation & $\mathbf{1 , 7 1}$ & $\mathbf{7 , 2 6}$ & $\mathbf{7 6 , 5 0}$ & $\mathbf{7}$ \\
X6: Know How & 1,69 & 7,19 & 83,69 & 8 \\
X9: Progress Technology & 1,52 & 6,45 & 90,14 & 9 \\
X10: Trading Partner & 1,32 & 5,61 & 95,74 & 10 \\
X11: Institution Support & 1,00 & 4,26 & 100,00 & 11 \\
\hline Jumlah & $\mathbf{2 3 , 5 5}$ & & \\
\hline
\end{tabular}

ditetapkan $75 \%$. Dari hasil pengumpulan data melalui jawaban responden yang terjaring dalam penelitian ini, maka semua sepakat bahwa hanya terdapat 7 (tujuh) dimensi yang benar-benar mempunyai tingkat kepentingan lebih dominan dibanding dimensi lainnya sehingga dengan urutan prioritas ditunjukkan pada Tabel 9 yang menyajikan sebuah urutan competitive priorities.

Dari hasil pengurutan prioritas ini dapat diperoleh informasi bahwa pada umumnya responden menyatakan bahwa quality (kualitas) sebagai titik berat dari kekuatan persaingan, dan dianggap lebih dominan dari variabel lain. Ini mengindikasikan bahwa kualitas produk masih merupakan syarat utama keunggulan bersaing industri. Cost/price pada urutan kedua menggambarkan bahwa produk dengan harga murah (akibat rendahnya biaya produksi) sebagai sarana untuk bertahan terhadap persaingan pasar. Delivery (sistem pengiriman) juga perlu menjadi bahan pertimbangan utama, sebab keterbatasan sarana prasarana transportasi akan mengakibatkan rendahnya mobilitas produk. Penyediaan sarana transportasi yang memadai sangat memengaruhi kualitas produk yang akan di distribusi dan memengaruhi ketepatan pengiriman, baik jumlah produk maupun waktu kirim (delivery time). Kendala IKM yang berada di pelosok pedesaan pada umumnya adalah sulitnya memasarkan produk akibat keterbatasan sarana transportasi.

\section{SIMPULAN}

Competitive priorities (prioritas keunggulan bersaing) industri dengan menggunakan pendekatan metode The Law Comparative Judgement (LCJ) memberikan informasi bahwa 76,50\% responden menilai dimensi Kualitas (Quality), Biaya (Cost/Price),
Sistem Pengiriman (Delivery), Fokus pada Konsumen (Customer Focus), Fleksibilitas (Flexibility), Kemampuan Berinovasi (Innovativeness), dan Berorientasi Pasar (Market Orientation) mempunyai tingkat kepentingan lebih dominan dibanding dengan Know-How, Progress Technology, Trading Partner dan Institution Support. Ketujuh dimensi/variabel penting tersebut merupakan dimensi competitive priorities yang harus diperhatikan dalam menyusun strategi bersaing industri, khususnya di Provinsi Gorontalo. Urutan competitive priorities industri ini pada dasarnya dapat diterapkan di daerah lain, mengingat karakteristik industri di Provinsi Gorontalo tidak jauh berbeda dengan daerah lainnya di Indonesia, yakni industri skala kecil dan menengah berbasis industri pangan, industri kerajinan dan industri pengolahan hasil pertanian.

\section{DAFTAR PUSTAKA}

Askar, M. and Mortagy, A.K., 2007. Assessing the Relative Importance of Competitive Priorities in Egyptian Companies, SAM Advanced Management Journal, Vol. 72, No. 3, pp. 35-46.

Dangayach, G.S and Deshmukh, S.G, 2001. Manufacturing Strategy: Literature Review and Some Issues, International Journal of Operations and Production Management, Vol. 21, No. 7, pp. 884-932.

Dangayach, G.S and Deshmukh, S.G, 2005. Advanced Manufacturing Technology Implementation; Evidence from Indian Small and Medium Enterprises (SMEs), Journal of Manufacturing Technology Management, Vol. 16, No. 5, pp. 483-496

Diaz, M.S., Gil, M.J.A., and Machuca, J.A.D., 2005. Performance Measurement Systems, Competitive Priorities, and Advanced Manufacturing Technology, International Journal of Operations \& Production Management, Vol. 25, No. 8, pp. 781-799 
Gonzalez, B.U and Vazquez, J.M.C., 2007. The Strategic Influence of Structural Manufacturing Decisions, International Journal of Operation \& Production Management, Vol. 27 No. 6, pp. 605-626.

Laosirihongthong, T. and Dangayach, G.S., 2005. A Comparative Study of Implementation of Manufacturing Strategies in Thai and Indian Automotive Manufacturing Companies, Journal of Manufacturing System, Vol. 24, No. 2, pp. 131-143.

Massa, S. and Testa, S., 2008. Innovation and SMEs: Misaligned Perspective and Goals Among Entrepreneurs, Academic, and Policy Makers, Journal of Technovation, No. 28, pp. 393-407.

Phusavat, K. and Kanchana, R., 2007. Competitive Priorities of Manufacturing Firm in Thailand, Industrial Management \& Data System, Vol. 107, No. 7, pp. 979-996.

Sekaran, U., 2003. Research Methods For Business: A Skill-Building Approach, $4^{\text {th }}$ edition, John Wiley \& Sons, Inc., New York.
Sharma, M. and Kodali, R., 2008. Development of a Framework for Manufacturing Excellence, Journal of Measuring Business Excellence, Vol. 12, No. 4, pp. 50-66.

Sharma, M. and Kodali, R., 2008. Validity and Reliability of Applying Manufacturing Excellence Frameworks to Indian Industries, Proceding ImechE, Vol. 222, Part B: J. Engineering Manufacture, pp. 723-739.

Supranto, J., 2004. Analisis Multivariat: Arti dan Interpretasi, PT. Rineka Cipta, Jakarta.

Takala, J., Hirvela, J., Liu, Y., and Malindzak, D., 2007. Global Manufacturing Strategies Require "Dynamic Engineers"? (Case Study in Finnish Industries), Industrial Management \& Data System, Vol. 107, No. 3, pp. 326-344.

Tambunan, T., 2007. Entrepreneurship Development: $\mathrm{SME}$ in Indonesia, Journal of Developmental Entrepreneursip, Vol. 12, No. 1, pp. 95-118. 